\title{
Effect of Topical Bromfenac In the Treatment of Central Serous Chorioretinopathy, A Study of 21 Cases
}

\author{
Nisar Ahmed Khan ${ }^{1 *}$, Aisha Khan², Atiqa Khan ${ }^{3}$, Sobia Khan ${ }^{4}$ and Aftab Ahmed Khan \\ ${ }_{1,4,5}$ Assistant Professor/Consultant, Indus Medical College Hospital, Pakistan \\ ${ }^{2}$ Isra University Hospital, Pakistan \\ ${ }^{3}$ Red Crescent Hospital, Pakistan
}

Submission: October 16, 2019; Published: October 23, 2019

*Corresponding author: Nisar Ahmed Khan, Assistant Professor/Consultant, Indus Medical College Hospital, Pakistan

\section{Purpose}

To monitor and confirm the effect of topical bromfenac nonsteroidal anti-inflammatory drug (NSAID) in the treatment of acute central serous chorioretinopathy at our facility.

Introduction: Central serous chorioretinopathy, a disorder mostly an idiopathic ocular disorder characterized by a serous detachment of the neurosensory retina at the macula, caused by active retinal pigment epithelial leakage. Although the exact pathophysiology of CSC has not been clearly elucidated, the primary abnormality leading to RPE disruption and leakage is thought to cause increase choroidal permeability. Studies using different imaging techniques have revealed the possible causes of abnormal permeability of the inner choroid. Ischemia and inflammation might lead to exudative changes within the choroid and the subsequent changes at the RPE. Topical bromfenac, ketorolac, nepafenac and diclofenac all belong to the NSAIDs class of medications. As an anti-inflammatory class, they function by inhibiting the enzyme cyclooxygenase, which blocks the synthesis of prostaglandins. A reduction in prostaglandin formation results a decrease in inflammation. It appears that the principle pathway involved in pain and inflammation is the cycloxygenase-2 pathway where nonsteroidal anti-inflammatory drugs (NSAIDs) seems to play a significant role.

Material and Method: It is an interventional, retrospective as well as prospective study conducted at Indus Medical College Hospital, Tando Mohammad Khan from February 2017-September 2019 includes 21 patients. Only patients with acute CSC included while those with chronic or recurrence were excluded. Careful history taken about sensitivity to bromfenac or any other non-steroidal anti-inflammatory drugs NSAIDs. All 21 patients were diagnosed as having acute CSC relying upon visual acuity by standard Snellen chart, dilated fundus exam using slit lamp (SHINNIPPON SL-203, Japan) with 90D lens and OCT (ocular coherence tomography by NIDEK, model RS-330 Japan) findings. All patients were treated by bromfenac topical drops twice daily. Patients followed on 5th day, 10th day and 30th day after presentation. Vision was recorded, dilated fundoscopy and OCT performed on each visit. All 21 patients were male (Table 1), divided into 3 age groups i.e. group A(21-30yrs) includes 11(52.38\%) patients, group B (31- 40 yrs.) includes 8(38.09\%) patients and group C (41-50 yrs ) includes 2(9.52\%) patient (Table 2). $9(42.85 \%)$ were right eyes, $12(57.14 \%)$ were left (Table 3). Vision recorded using standard Snellen chart, 11(36.52.38\%) patients having vision $0.4,5(33.33 \%)$ were $0.2,3(14.28 \%)$ were having 0.1 while remaining $2(9.52 \%)$ were recorded as CF at 1 meter (Table 4 ).

Macular thickness recorded using OCT, patients again divided into 3 groups on OCT findings, group 1, 12(57.14\%) patients having macular thickness between 422-485 microns, group 2, 7(33.33\%) patients between 535-565 microns while group 3, includes 2(9.52.\%) patients having thickness between 612-644 microns (Table 5). All 21 patients received topical bromfenac, one drop twice daily to treat acute CSC for 10 days and monitor for 1 month.

Results: This interventional study includes 21 patients who were diagnosed as acute CSC and followed from the day of presentation to 30 th day. All 21 patients were undergoing intervention by using topical bromfenac eye drop, one drop twice daily for 30 days. Macular thickness and visual acuity recorded from the day of presentation up to 30th day. (Table 6) shows all changes before and after treatment and (Figure 1-4) shows early resolution of sub-macular fluid in one of these patients treated with topical bromfenac eye drops (one drop twice daily). In group 1 the macular thickness (CFT) improve from 422-485 microns at onset to 317-382 microns on 5th day becomes 246-295 on 10th day while 210-226 on 30th day. Vision improved from 0.4 to 0.7 at 5 th day, improved to 0.8 on 10th day and remained same on 30th day. In group 2 the CFT reduced from 535-565 microns to 401-440 microns on 5th day becomes 318310 on 10th day and on 30th day it was 221-232 microns with improvement in visual acuity which was 0.2 at onset to 0.6 at 5 th day, 0.7 at 10 th day and improved to 0.8 on 30 th day. In group 3 the CFT reduced from $657-722$ microns to 456-469 microns on 5th day, 259-366 microns on 10th day while 206-227 microns on 30th day. Visual acuity improved from CF at onset to 0.4 on 5 th day, 0.6 on 10 th day and improved to 0.7 on 30 th day. Conclusion: This, simple, safe, affordable and easily available treatment modality in all parts of the world with early rehabilitation of acute CSC patients. 
Keywords: 21 Cases; Treatment; Bromfenac; Central serous chorioretinopathy (CSC); Indus medical college hospital.

\section{Introduction}

Central serous chorioretinopathy (CSC) is an idiopathic disorder characterized by a serous detachment of the neurosensory retina at the macula [1], which is caused by active retinal pigment epithelial (RPE) leakage [2,3]. The disease has a favorable natural course with the spontaneous resolution of the neurosensorial detachment in association with improvement of visual function. However, it is very difficult to predict the prognosis of CSC, and in some cases, progressive visual loss may be seen $[4,5]$. Although the exact pathophysiology of CSC has not been clearly elucidated, the primary abnormality leading to RPE disruption and leakage is thought to be increased choroidal permeability [6]. Studies using different imaging techniques have revealed the possible causes of abnormal permeability of the inner choroid. Ischemia and inflammation might lead to exudative changes within the choroid and the subsequent changes at the RPE $[7,8]$.

Diclofenac, bromfenac, ketorolac, nepafenac and all belong to the non-steroidal anti-inflammatory drugs (NSAIDs) class of medications. As an anti-inflammatory class, they function by inhibiting the enzyme cyclooxygenase, which blocks the synthesis of prostaglandins. A reduction in prostaglandin formation results decrease in inflammation. Inflammation makes the blood-retinal barrier more permeable. It appears that the principle pathway involved in pain and inflammation is the cyclooxygenase - 2 pathways where non-steroidal antiinflammatory drugs NSAIDs seems to play a significant role. The current uses for topical NSAIDs have been somewhat limited to the prevention of intraoperative miosis (small pupil) during Phacoemulsification $[9,10]$, relief of postoperative pain, inflammation and photophobia [11], therapy for ocular atopy [12] and the reduction of post-cataract cystoid macular edema [13].

\section{Materials and Methods}

It is an interventional, retrospective as well as prospective study conducted at Indus Medical College Hospital, Tando Mohammad Khan from February 2017 to September 2019 includes 21 patients. Only patients with acute CSC included while those with chronic or recurrence were excluded. Careful history taken about sensitivity to bromfenac or any other nonsteroidal anti-inflammatory drugs NSAIDs. All 21 patients were diagnosed as having acute CSC relying upon visual acuity by standard Snellen chart, dilated fundus exam using slit lamp (SHIN-NIPPON SL-203, Japan) with 90D lens and OCT (ocular coherence tomography by NIDEK, model RS-330 Japan) findings. All patients were treated by bromfenac topical drops twice daily. Patients followed on 5th day, 10th day and 30th day after

presentation. Vision was recorded, dilated fundoscopy and OCT performed on each visit.

All 21 patients were male (Table 1), divided into 3 age groups i.e. group A(21-30yrs) includes 11(52.38\%) patients, group B (31- $40 \mathrm{yrs}$ ) includes $8(38.09 \%)$ patients and group C (41-50 yrs.) includes 2(9.52\%) patient (Table 2). 9(42.85\%) were right eyes, $12(57.14 \%)$ were left (Table 3). Vision recorded using standard Snellen chart, $11(36.52 .38 \%)$ patients having vision $0.4,5(33.33 \%)$ were $0.2,3(14.28 \%)$ were having 0.1 while remaining $2(9.52 \%)$ were recorded as CF at 1 meter (Table 4). Macular thickness recorded using OCT, patients again divided into 3 groups on OCT findings, group 1, 12(57.14\%) patients having macular thickness between 422-485 microns, group 2, $7(33.33 \%)$ patients between 535-565 microns while group 3, includes 2(9.52.\%) patients having thickness between 657-722 microns (Table 5). All 21 patients received topical bromfenac, one drop twice daily to treat acute CSC for 10 days and monitor for 1 month.

Table 1: Male Female Ratio.

\begin{tabular}{|c|c|}
\hline Male & Female \\
\hline $21(100 \%)$ & Nil \\
\hline
\end{tabular}

Table 2: Age Groups.

\begin{tabular}{|c|c|c|}
\hline Group A(21-30yrs) & Group B(31-40yrs) & Group C(41-50yrs) \\
\hline $11(52.38 \%)$ & $8(38.09 \%)$ & $2(9.52 \%)$ \\
\hline
\end{tabular}

Table 3: Laterality.

\begin{tabular}{|c|c|}
\hline Right Eye & Left Eye \\
\hline $9(42.85 \%)$ & $12(57.14 \%)$ \\
\hline
\end{tabular}


Table 4: Vision at onset.

\begin{tabular}{|c|c|}
\hline Patients & Vision \\
\hline $11(52.38 \%)$ & 0.4 \\
\hline $5(23.80 \%)$ & 0.2 \\
\hline $3(14.28 \%)$ & 0.1 \\
\hline $2(9.52 \%)$ & CF at 1 meter \\
\hline
\end{tabular}

Table 5: Macular Thickness at onset.

\begin{tabular}{|c|c|c|}
\hline Groups & Patients & Macular Thickness \\
\hline 1 & $12(57.14 \%)$ & $422-485$ microns (um) \\
\hline 2 & $7(33.33 \%)$ & $535-565$ microns (um) \\
\hline 3 & $2(9.52 . \%)$ & $657-722$ microns (um) \\
\hline
\end{tabular}

\section{Results}

This interventional retrospective as well as prospective study includes 21 patients who were diagnosed as acute CSC and followed from the day of presentation to 30th day. All 21 patients were undergoing intervention by using topical bromfenac eye drop, one drop twice daily for 30 days. Macular thickness and visual acuity recorded from the day of presentation up to 30th day. (Table 6) shows all changes before and after treatment and (Figure 1-8) shows early resolution of sub-macular fluid in one of these patients treated with topical bromfenac eye drops (one drop twice daily). In group 1 the macular thickness (CFT) improve from 422-485 microns at onset to 317-382 microns on 5th day becomes $246-295$ on 10th day while $210-226$ on 30th day. Vision improved from 0.4 to 0.7 at 5 th day, improved to 0.8 on 10th day and remained same on 30th day. In group 2 the CFT reduced from 535-565 microns to 401-440 microns on 5th day becomes 318-310 on 10th day and on 30th day it was 221-232 microns with improvement in visual acuity which was 0.2 at onset to 0.6 at 5 th day, 0.7 at 10th day and improved to 0.8 on 30th day. In group 3 the CFT reduced from 657-722 microns to 456-469 microns on 5th day, 259-366 microns on 10th day while 206-227 microns on 30th day. Visual acuity improved from CF at onset to 0.4 on 5 th day, 0.6 on 10 th day and improved to 0.7 on 30 th day.

Table 6: Macular thickness in microns and visual acuity before and after intervention with topical bromfenac eye drop.

\begin{tabular}{|c|c|c|c|c|c|c|}
\hline \multirow{3}{*}{ Days } & \multicolumn{6}{|c|}{ Groups } \\
\hline & \multicolumn{2}{|c|}{1} & \multicolumn{2}{|c|}{2} & \multicolumn{2}{|c|}{3} \\
\hline & CFT (Microns) & Vision & CFT (Microns) & Vision & CFT (Microns) & Vision \\
\hline At onset & $422-485$ & 0.4 & $535-565$ & 0.2 & $657-722$ & $\mathrm{CF}$ \\
\hline 5 th & $317-382$ & 0.7 & $401-440$ & 0.6 & $456-469$ & 0.4 \\
\hline 10 th & $246-295$ & 0.8 & $318-310$ & 0.7 & $259-366$ & 0.6 \\
\hline 30th & $210-226$ & 0.8 & $221-232$ & 0.8 & $206-227$ & 0.7 \\
\hline
\end{tabular}

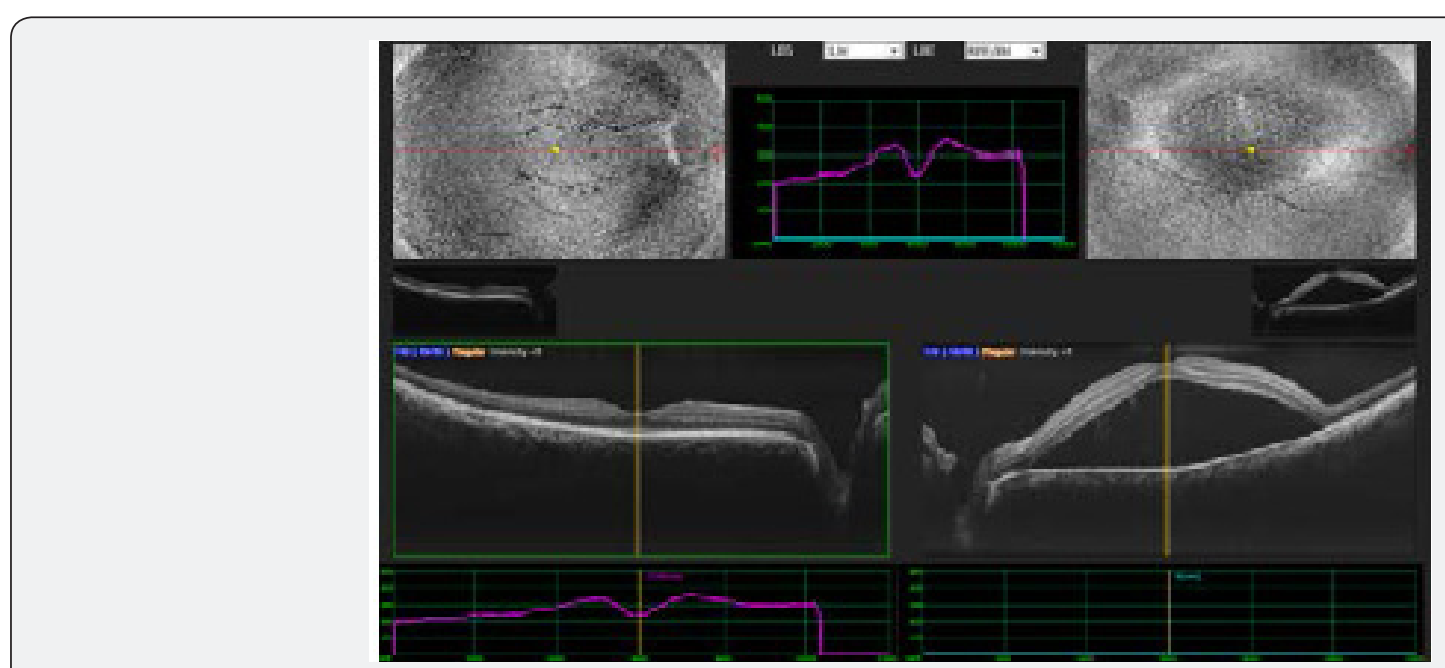

Figure 1: At presentation. 


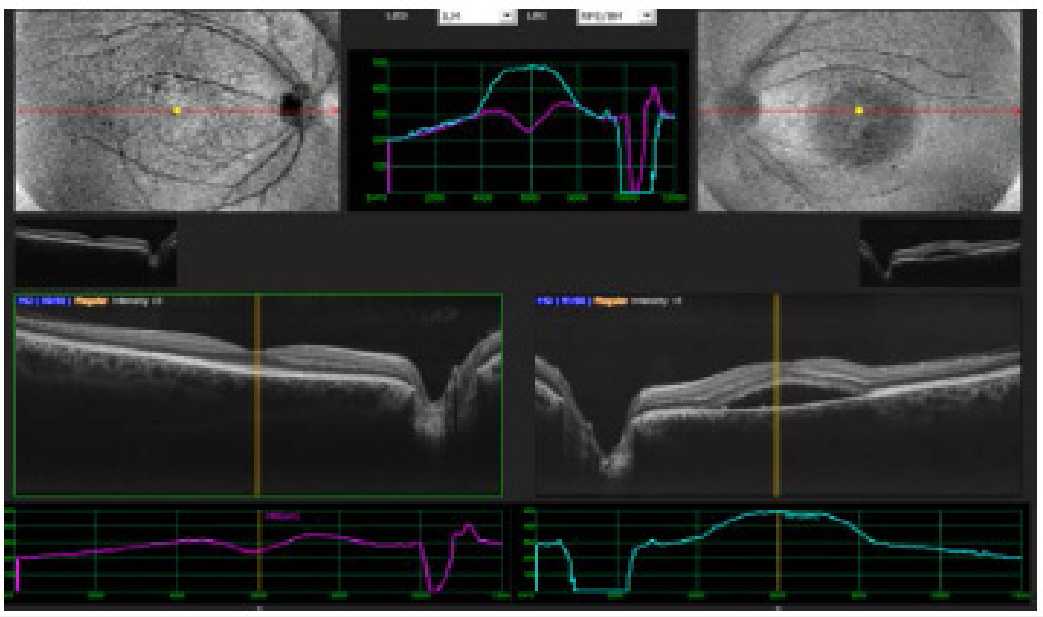

Figure 2: 5th Day.

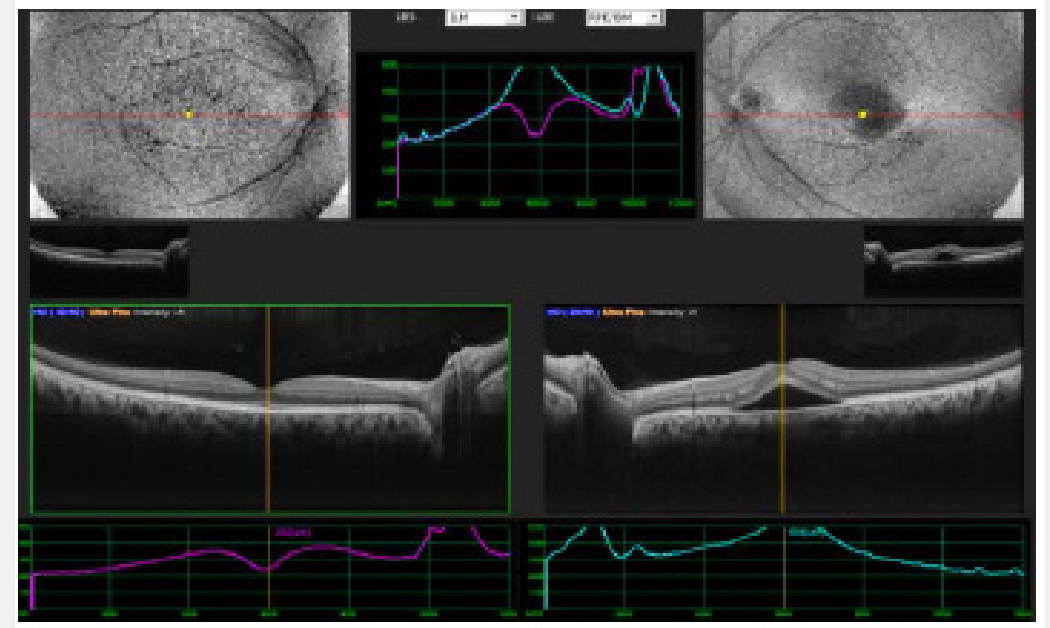

Figure 3: 10th Day.

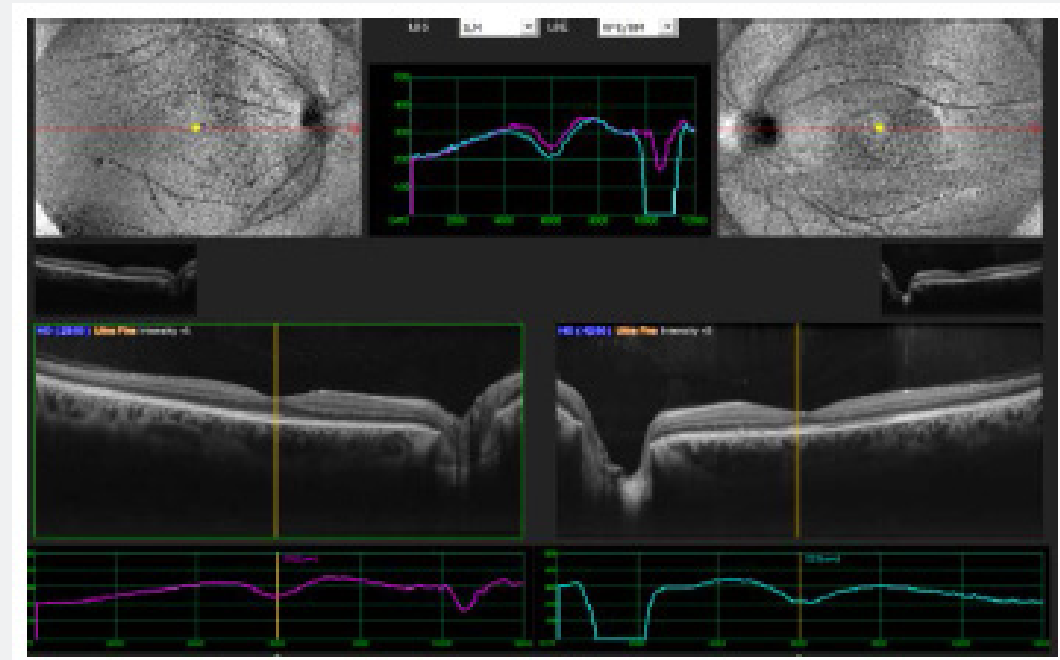

Figure 4: 30th Day.

Note: Figure 1,2,3 and 4: Showing reduction of CFT in left eye from 722 microns at onset to 469 microns at 5 th day and 366 microns at 10 th day while 227 microns at 30 th day with only topical bromfenac eye drops. 


\section{JOJ Ophthalmology}

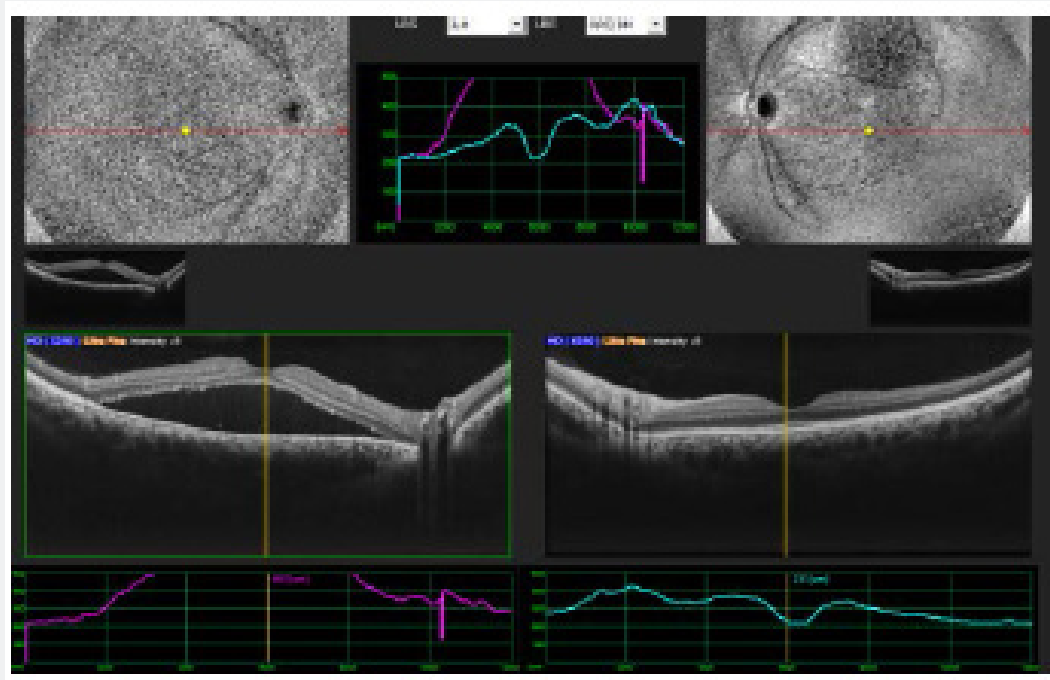

Figure 5: At presentation.

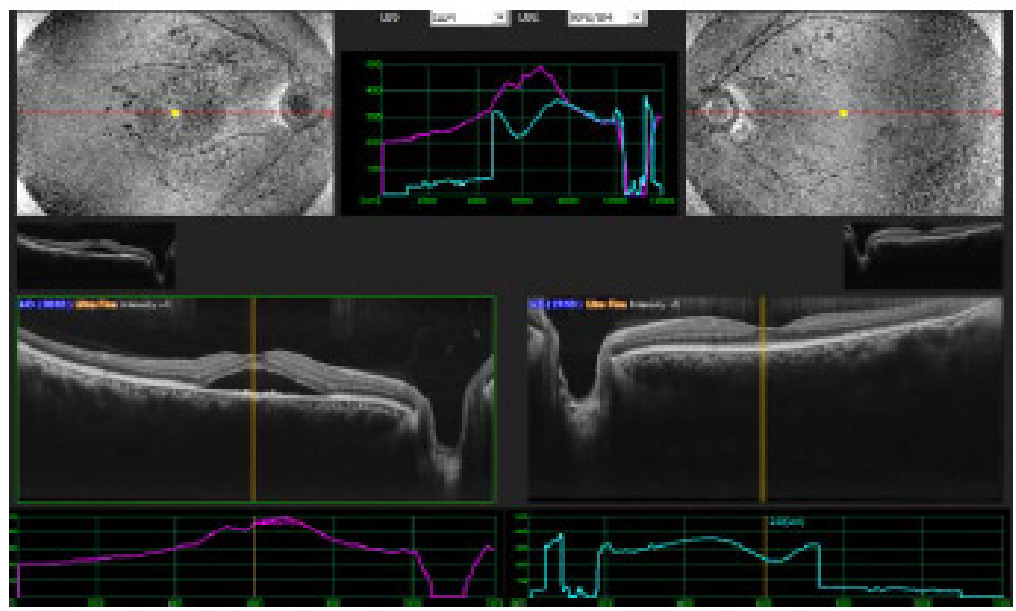

Figure 6: 5th Day.

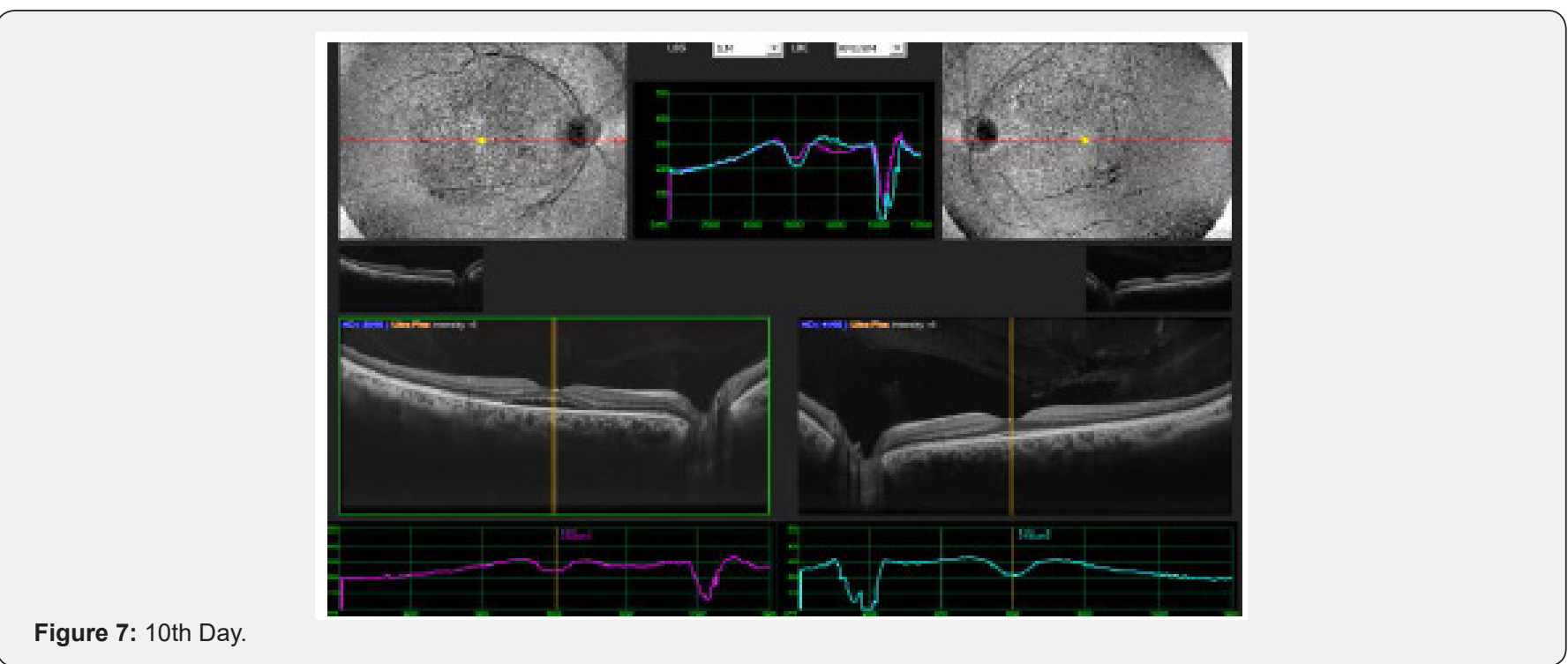




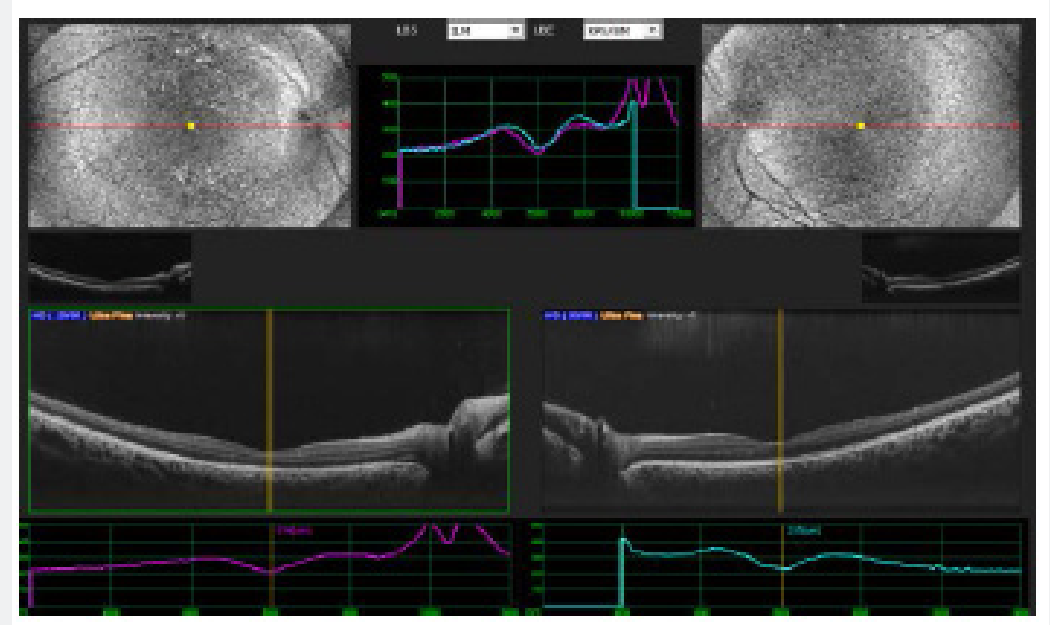

Figure 8: 30th Day.

Note: Figure 5,6,7 and 8: Showing reduction of CFT in right eye from 657 microns at onset to 456 microns at 5 th day and 259 microns at 10 th day while 206 microns at 30 th day with only topical bromfenac eye drops.

\section{Discussion}

Central serous chorioretinopathy an idiopathic retinal disorder can leads to visual loss because of the accumulation of fluid in retinal layers for longer time that may leads to foveal attenuation, cystoid macular degeneration, and damage of the foveal photoreceptor layer [14-16] some therapeutic intervention may be helpful to resorb this fluid quickly and avoid dyschromatopsia and metamorphopsia along with other visual problems. Variety of treatment modalities like focal argon photocoagulation, PDT, anti-VEGF, topical non-steroidal antiinflammatory drug (NSAID) are being used. In this study we used only bromfenac, one of the non- steroidal anti-inflammatory drug NSAIDs as topical therapy. We did not use any intravitreal injection, laser or PDT. We found that macular thickness reduced very early and vision returned to normal in those patients who received topical bromfenac.

[17] showed in their study that average macular thickness at center of the fovea before treatment was 431.55 microns, and post treatment macular average thickness was 198.77 microns though they treated CSR with Intravitreal bevacizumab along with laser. We got the same outcomes using bromfenac topical therapy. Zeynep Alkin and coworkers [18] used topical nepafenac $0.1 \%$, and they have $82.3 \%$ results in resolution of macular sub retinal fluid at six months with the CFT decrease 349 microns to 257 at 1 month, 248 microns at 3 months and 221 at 6 months while in control group resolution was $42.8 \%$ with macular thickness reduced from 391 to 320 microns at 1 month 316 microns, at 3 months 301 microns and at six months 301 microns. We got better results using topical bromfenac only and within 10 days though we followed these patients for 1 month. Furthermore, no ocular or systemic side effects were observed in the treatment group during the follow-up period.
[19] in their study, 63 patients treated with acute CSC using half-dose verteporfin PDT or placebo PDT to demonstrate the safety of PDT. Subsequent to a follow-up time of 12 months, 94\% of the eyes exhibited complete resolution of serous macular detachment in the half-dose PDT group versus only $57 \%$ of the eyes in the placebo group. Again, our results prove bromfenac topical therapy is more effective. [20-22] showed in their studies that treatment of acute CSC with intravitreal injections of antiVEGF agents has variable outcomes. Our results with topical bromfenac were excellent and consistent. [23] demonstrated limited recovery in CSC patients with acetazolamide. In addition, its use is limited because of its potential side effects. It has been proposed that corticosteroid antagonists could be used for treatment of acute CSC such as mifepristone and ketoconazole. However, trials with these drugs have proven unsuccessful [24,25]. Metoprolol and propranolol, another treatment strategy with adrenergic receptor inhibitors, should be used very cautiously because of its significant side effects and potential morbidity [26]. In our experience bromfenac shows better results without any side effects. This somehow proves that bromfenac topical therapy like other NSAIDs has its role for early rehabilitation of these patients suffering with acute CSC.

\section{Conclusion}

Number of studies being conducted by renowned researchers all over the world to treat acute central serous chorioretinopathy using many modalities of treatment like argon photocoagulation for leaking spot, PDT, anti-VEGF injections, topical antiinflammatory (NSAIDs) etc., all are having their worth but in this study, we used only topical bromfenac drops (one drop twice daily) and within 10 days, macular thickness as well as visual acuity came to almost at normal level. This treatment modality is safe, affordable and easily available. 


\section{Acknowledgement}

I am thankful to Aisha Khan (MBBS), Atiqa Khan (BDS), at Isra University Hospital Pakistan for their help in compiling data. Special thanks to Sobia Khan (4th year MBBS) student, at Indus Medical College Hospital and my assistant Mr. Moin Shaikh for their help to keep OCT record. I am also thankful to Dr. Aftab Ahmed Khan (assistant professor), at Indus Medical College Hospital, for his continuously enormous support.

\section{References}

1. Jack J Kanski (2011) Clinical Ophthalmology: A Systemic approach $\left(7^{\text {th }}\right.$ edn) Pp.632.

2. Wang M, Munch IC, Hasler PW, Prünte C, Larsen M (2008) Central serous chorioretinopathy. Acta Ophthalmol 86(2): 126-145.

3. Piccolino FC, Borgia L (1994) Central serous chorioretinopathy and indocyanine green angiography. Retina 14(3): 231-242.

4. Loo RH, Scott IU, Flynn HW, Gass JD, Murray TG, et al. (2002) Factors associated with reduced visual acuity during long-term follow-up of patients with idiopathic central serous chorioretinopathy. Retina 22(1): 19-24.

5. Levine R, Brucker AJ, Robinson F (1989) Long-term follow-up of idiopathic central serous chorioretinopathy by fluorescein angiography. Ophthalmology 96(6): 854-859.

6. Guyer DR, Yannuzzi LA, Slakter JS, Sorenson JA, Ho A, et al. (1994) Digital indocyanine green videoangiography of central serous chorioretinopathy. Arch Ophthalmol 112(8): 1057-1062.

7. Tittl MK, Spaide RF, Wong D, Pilotto E, Yannuzzi LA, et al. (1999) Systemic findings associated with central serous chorioretinopathy. Am J Ophthalmol 128(1): 63-68.

8. Prünte C, Flammer J (1996) Choroidal capillary and venous congestion in central serous chorioretinopathy. Am J Ophthalmol 121(1): 26-34.

9. Ohara K, Ohbuto A, Miyamoto T, Miyakubo H, Nezu N (2004) Prevention of miosis during cataract surgery by topical bromfenac sodium. Jpn J Clin Ophthalmol 58: 1325-1328.

10. Data on file. ISTA Pharmaceuticals Xibrom US Phase 111 Trials.

11. Seward MS, Cooke DL, Grillone LR, Sacks RM (2006) Bromfenac Study Group Topical Xibrom 0.09\% Significantly Reduced Ocular Pain Following Cataract Surgery. Presented at ARVO, Fort Lauderdale, Florida, USA, Poster B600 47(13): 679.

12. Miyake K, Masuda K, Shirato S, Oshika T, Eguchi K, et al. (2000) Comparison of diclofenac and fluorometholone in preventing cystoid macular edema after small incision cataract surgery: a multicentered prospective trial. Jpn J Ophthalmol 44(1): 58-67.
13. Schainus R (2003) Topical nonsteroidal anti-inflammatory therapy in Ophthalmology. Ophthalmologica 217(2): 89-98.

14. Piccolino FC, de la Longrais RR, Ravera G, Eandi CM, Ventre L, et al. (2005) The foveal photoreceptor layer and visual acuity loss in central serous chorioretinopathy. Am J Ophthalmol 139(1): 87-99.

15. Iida T, Yannuzzi LA, Spaide RF, Borodoker N, Carvalho CA, et al. (2003) Cystoid macular degeneration in chronic central serous chorioretinopathy. Retina 23(1): 1-7.

16. Shukla D, Kolluru C, Vignesh TP, Karthikprakash S, Kim R, et al. (2006) Transpupillary thermotherapy for subfoveal leaks in central serous chorioretinopathy. Eye (Lond) 22(1): 100- 106.

17. Lucía Villarroel Salvatierra (2016) Study of Best Corrected Visual Acuity and Macular Thickness After Bevacizumab or Bevacizumab with Laser in Acute Central Serous Chorioretinopathy. EC Ophthalmology 4.4: 569-578.

18.Zeynep Alkin, Ozen Ayranci Osmanbasoglu, Abdullah Ozkaya, Gonul Karatas, Ahmet Taylan Yazici (2013) Med Hypothesis Discov Innov Ophthalmol. Winter 2(4): 96-101.

19. Chan WM, Lai TY, Lai RY, Liu DT, Lam DS (2008) Half-dose verteporfin photodynamic therapy for acute central serous chorioretinopathy. Ophthalmology 115(10): 1756-1765.

20. Artunay O, Yuzbasioglu E, Rasier R, Sengul A, Bahcecioglu H (2010) Intravitreal bevacizumab in treatment of idiopathic persistent central serous chorioretinopathy: a prospective, controlled clinical study. Curr Eye Res 35(2): 91-98.

21. Ober MD, Yannuzzi LA, Do DV, Spaide RF, Bressler NM, et al. (2005) Photodynamic therapy for focal retinal pigment epithelial leaks secondary to central serous chorioretinopathy. Ophthalmology 112(12): 2088-2094.

22. Lim JW, Ryu SJ, Shin MC (2010) The effect of intravitreal bevacizumab in patients with acute central serous chorioretinopathy. Korean J Ophthalmol 24(3): 155-158.

23. Pikkel J, Beiran I, Ophir A, Miller B (2002) Acetazolamide for central serous retinopathy. Ophthalmology 109(9): 1723-1725.

24. Meyerle CB, Freund KB, Bhatnagar P, Shah V, Yannuzzi LA (2007) Ketoconazole in the treatment of chronic idiopathic central serous chorioretinopathy. Retina 27(7): 943-946.

25. Nielsen JS, Jampol LM (2011) Oral mifepristone for chronic central serous chorioretinopathy. Retina 31(9): 1928-1936.

26. Avci R, Deutman AF (1993) Treatment of central serous choroidopathy with the beta receptor blocker metoprolol (preliminary results) Klin Monbl Augenheilkd 202(3): 199-205. 
This work is licensed under Creative Commons Attribution 4.0 License DOI: $10.19080 /$ JOJO.2019.08.555727

Your next submission with Juniper Publishers
will reach you the below assets
- Quality Editorial service
- Swift Peer Review
- Reprints availability
- E-prints Service
- Manuscript Podcast for convenient understanding
- Global attainment for your research
- Manuscript accessibility in different formats
( Pdf, E-pub, Full Text, Audio)
- Unceasing customer service
Track the below URL for one-step submission
https://juniperpublishers.com/online-submission.php

